www.jmscr.igmpublication.org

Impact Factor 5.84

Index Copernicus Value: 71.58

ISSN (e)-2347-176x ISSN (p) 2455-0450

crossref DOI: _https://dx.doi.org/10.18535/jmscr/v5i9.38

\title{
Cystic Space Occupying Lesion (Sol) of Pancreas - Not Always Malignant
}

Authors

Dr Sathish Kumar K Mch Resident, Prof. Jeswanth S Mch, Prof. Ravichandran P Mch, Prof. Sugumar C Mch, Dr Senthil Kumar P Mch, Dr Kamalakannan R Mch, Dr Saravanan J Mch, Dr Umamageshwaran M Mch, Dr Thiruvarul M Mch Institute of Surgical Gastroenterology and Liver Transplant, Govt Stanley Medical College and Hospital, Chennai, Tamil Nadu

Corresponding Author

Dr Sathish Kumar K

Address - No 65, Westmada Street, Thiruvottiyur, Chennai - 600019

Email: k_sathish123@yahoo.com, Contact no-9841596047

\section{INTRODUCTION}

Development of abdominal TB is independent of pulmonary disease with a reported incidence of 5$10 \%$ of all extrapulmonary sites involved. Organs commonly affected in TB abdomen includes liver, spleen, bowel, peritoneum and mesenteric nodes. Isolated pancreatic TB is a rare clinical entity seen only in approximately $8.3 \%$ of abdominal TB patients with only a hand full of cases been reported so far. In a study conducted by Bhansali et. Al with 300 patients of abdominal TB, not even a single patient had pancreatic involvement proving the rarity of this condition. ${ }^{(1)}$ Pancreatic TB is commonly seen in TB dissemination or in immunocompromised patients. $^{(2,3)}$

Isolated TB pancreas commonly presents as discrete pancreatic mass often mimicking pancreatic malignancy or pyogenic pancreatitis, most commonly seen in young individuals with $50 \%$ of cases reported so far aged between 20$30 y r s .{ }^{(4)}$ Early suspicion and diagnosis is needed as these patients have an excellent outcome to standard ATT treatment. We herewith report a case of isolated pancreatic TB for its rarity.

Keywords: pancreas, tuberculosis, cystic neoplasm.

\section{CASE REPORT}

A 22 year old female who was under evaluation for primary infertility in department of obstetrics and gynaecology, Government Stanley hospital was referred to Institute of Surgical Gastroenterology and liver transplantation, Government Stanley hospital for opinion regarding an incidental finding of cystic space occupying lesion of pancreas found in Ultrasonogram screening for infertility. Patient presented with vague non specific symptoms like generalized myalgia and loss of appetite for the past 3 months. Bowel/ Bladder habits were normal and she denied prior history of anti tuberculosis treatment or close contact with the TB patient.

\section{ON EXAMINATION}

Patient belonged to ECOG performance status I, moderately built and nourished, had no pallor/icterus/ pedal edema. Her abdomen was soft, non tender, no organomegaly and there was no evidence of free fluid in the abdomen. Respiratory and cardiovascular system examination were normal. 


\section{INVESTIGATION}

Routine blood investigation revealed anemia, normal liver and renal function test, serum amylase, lipase levels were normal, CRP negative, tumor markers -CA 19.9 and CEA negative, viral markers and mantoux were negative. Esophago gastroduodenoscopy showed an extraneous impression over D1/D2 junction and there was no oesophageal or fundal varices.

\section{IMAGING}

$>$ CHEST XRAY was normal.

$>$ USG Abdomen (fig: 1) revealed a cystic space occupying lesion over the neck/body of pancreas measuring approximately $6 \times 5 \times 4 \mathrm{cms}$.

$>$ CECT Abdomen (Fig: 2) showed a well defined cystic space occupying lesion over the neck and body of pancreas of size $5.5 \times 4.7 \times 3.3 \mathrm{cms}$, with central area of hypoattenuation and peripheral hyperattenuation. Spleno portal axis was normal, SMA/SMV was free from the lesion.

$>$ USG guided aspirate analysis (Table -1$)$ Gene xpert positive for Mycobacterium tuberculosis.

\section{TREATMENT}

Patient was started on category I Anti tuberculous treatment currently under regular follow up, showing good clinical and radiological response to ATT

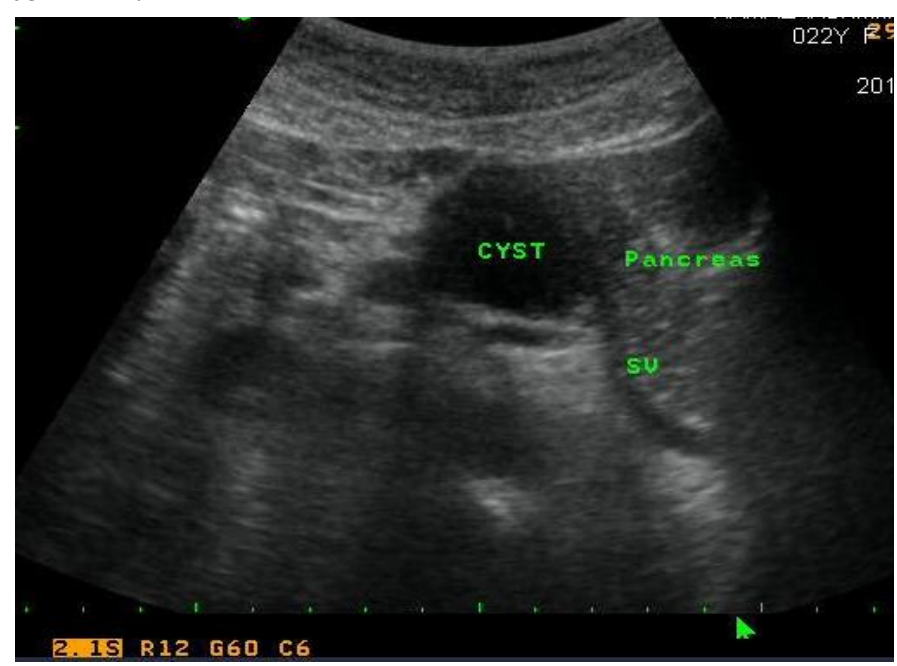

Fig 1 USG Abdomen Showing Cystic Sol Pancreas

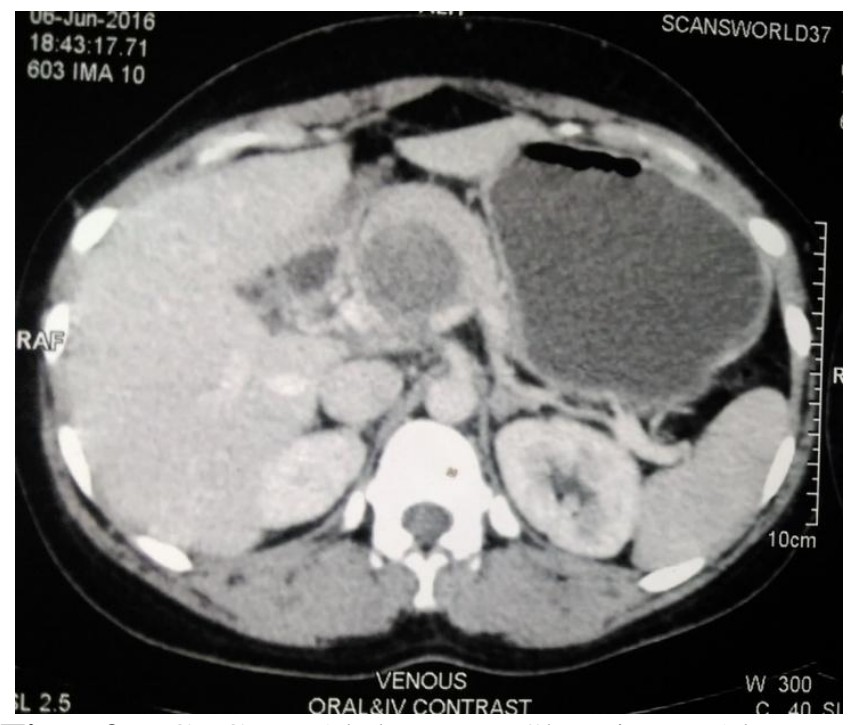

Fig 2 CECT Abdomen Showing Abscess Involving Head and Neck of Pancreas.

Table - 1 : USG guided aspirate analysis

\begin{tabular}{|l|l|}
\hline Amylase & 73U/1 \\
\hline Cytology & Eosinophilic aspirate \\
\hline AFB smear/ culture & Negative \\
\hline Gene xpert & $\begin{array}{l}\text { Positive for Mycobacterium } \\
\text { tuberculosis and sensitive to rifampicin }\end{array}$ \\
\hline
\end{tabular}

\section{DISCUSSION}

\section{PATHOGENESIS}

Although primary invasion of TB bacilli is not usually evident in most cases of pancreatic TB, several mechanisms have been postulated. Contiguous infection from peripancreatic node or rarely from hematogenous spread are the most acceptable among them. ${ }^{(5)}$ Most common sites are head and uncinate process of pancreas. ${ }^{(6,7)}$

\section{CLINICAL PRESENTATION}

Pancreatic TB can present as solid/cystic mass lesion, abscess, lymphoma, pseudocyst or acute/chronic pancreatitis. ${ }^{(8)}$ Presence of vascular invasion does not rule out the possibility of pancreatic TB. ${ }^{(9)}$ Common bile duct and pancreatic duct are usually preserved, inspite of the lesion being located in pancreatic head in contrary to malignancy.

Most common symptom include non-specific abdominal pain, fever, anorexia and weight loss. ${ }^{(10,11,12,13,14)}$ Less common symptoms are iron deficiency anemia, vomiting, obstructive jaundice, hematemesis and portal hypertension. ${ }^{(6,15,16)}$ 
$\mathrm{Xia}$ and colleagues reported 16 patients with pancreatic TB and the presenting symptoms were abdominal pain (75-100\%), weight loss (69\%), malaise $(64 \%)$, fever and night sweats $(50 \%){ }^{(17)}$

Laboratory abnormalities include anaemia, decreased WBC, increased OT/PT, increased ALP in $50 \%$ cases. $^{(17)}$ Tuberculin skin test is positive with an induration of moe than $10 \mathrm{~mm}$ in $50 \%$ cases but a negative mantoux does not rule out pancreatic TB. ${ }^{(2)}$

\section{IMAGING}

Pancreatic TB can be classified radiologically into 3 types. A) mass forming B) diffuse form C) small nodular form, of which mass forming type is more common seen in approx. $94 \%$ cases. ${ }^{(18)}$

Although imaging modalities like USG, CT, MRI may suggest the possibility of pancreatic TB none are neither specific nor pathognomic. ${ }^{(19)}$

USG usually shows diffusely enlarged pancreas with focal hypoechoeic lesions or a cystic lesion. ${ }^{(19,20)}$ Associated findings include peripancreatic/mesenteric adenopathy, bowel wall thickening and ascites. ${ }^{(19)}$

CT abdomen reveals mass lesion over the head/ uncinate process of pancreas. Peripheral ring enhancement of nodes are visible on i.v contrast. ${ }^{(10,18,23)}$

EUS-FNA aspirate from the lesion and performing bacterial culture, cytology, AFB staining is usually needed in majority of cases but definitive diagnosis is based on HPE and microbiological confirmation (gene xpert/ PCR). ${ }^{(22-29)}$

In a study done by Song et al $76.2 \%$ of patients with pancreatic TB were diagnosed by EUS-FNA of which $75 \%$ had histopathological evidence of caseating granuloma ${ }^{(30)}$ and $20-40 \%$ had microbiological confirmation of AFB. ${ }^{(27)}$

\section{TREATMENT}

Multidrug antituberculous chemotherapy is given for a period of 6-12 months. Response to ATT is usually excellent, but follow-up is always needed in these patient to rule out the rare possibility of TB co-existing with malignancy. ${ }^{(10,11,12,14,21,31,32)}$
When diagnosis and treatment is delayed this condition carries a mortality rate of $10.8 \%$. for those patients with very large mass minimallt invasive procedures like endoscopic internal drainage, percutaneous catheter drainage or biliary stenting can be performed undercover of ATT. ${ }^{(33)}$

\section{CONCLUSION}

High index of suspicion is needed to diagnose pancreatic TB especially in TB endemic like India.

Pancreatic mass in an young individual, possibility of tuberculosis should be considered in differential diagnosis.

Utilization of EUS with biopsy and latest molecular diagnostic techniques like gene xpert might help in differentiating this benign pathology from malignancy.

\section{REFERENCES}

1. Bhansali SK. Abdominal tuberculosis. Am J Gastroenterol. 1977;67:324-7

2. Sharma SK, Mohan A. Extrapulmonary tuberculosis. Indian J Med Res. 2004;120: 316-53.

3. Haddad F. Abdominal tuberculosis. Dis Colon Rectum. 1988;31:333.

4. Isolated pancreatic tuberculosis masquerading as pancreatic cancer. George S. Zacharia, Rajany Antony, Sandesh Kolassery, and Thazhath $\mathrm{M}$. Ramachandran "Gastroenterol Rep (Oxf). 2014 May; 2(2): 154-157.2014 Mar 19. doi: 10.1093/gastro/gou017

5. Franco-Paredes $\mathrm{C}$ et al. Tuberculosis of the pancreas: report of two cases and review of literature. American journal of the medical sciences, 2002, 323:54-8.

6. Crowson MC, Perry M, Burden E. Tuberculosis of the pancreas: a rare cause of obstructive jaundice. $\mathrm{Br} \quad \mathrm{J}$ Surg 1984;71:239. [PMID: 6697132]

7. Teo LL, Venkatesh SK, Ho KY. Clinics in diagnostic imaging. Singapore. Med J 2007; 48:687-692. [PMID: 17609835] 
8. Pancreatic Tuberculosis: An Overview. Shabnam Shahrokh et al. JOP. J Pancreas (Online) 2015 May 20; 16(3):232-238.

9. Rana SS, Sharma V, Sampath S, Sharma R, Mittal BR, Bhasin DK.Vascular invasion does not discriminate between pancreatic tuberculosis and pancreatic malignancy: a case series. Ann Gastroenterol 2014;27:395-398.[PMID: 25331582]

10. Ladas SD, Vaidakis E, Lariou C, et al. Pancreatic tuberculosis in nonimmunocompromised patients: reports of two cases and a literature review. Eur J Gastroenterol Hepatol. 1998;10:973-6.

11. Lo SF, Ahchong AK, Tang CN, Yip AW. Pancreatic tuberculosis: case reports and review of the literature. J R Coll Surg Edinb. 1998;43:65-8.

12. Brusko G, Melvin WS, Fromkes JJ, Ellison ES. Pancreatic tuberculosis. Am Surg. 1995;61:513-5.

13. Jena GP, Manoharan GR, Mbete DL, Pillay SS. Tuberculous pancreatic abscess in HIV-positive patients. A report of three cases and a review of the literature. S Afr J Surg. 1999;37:69-71.

14. Wu CS, Wang SH, Kuo TT. Pancreatic tuberculosis mimicking pancreatic head carcinoma: a case report and review of the literature. Infection. 1994;22:287-9.

15. Zalev AH, Sacks JS, Warren RE. Pancreaticoduodenal tuberculosis simulating metastatic ovarian carcinoma. Can J Gastroenterol. 1997;11:41-3.

16. Fan ST, Yan KW, Lau WY, Wong KK. Tuberculosis of the pancreas: a rare cause of massive gastrointestinal bleeding. $\mathrm{Br} \mathrm{J}$ Surg. 1986;73:373.

17. Xia $\mathrm{F}$ et al. Tuberculosis of pancreas and peripancreatic lymph nodes in immunocompetent patients: experience from China. World journal of gastroenterology, 2003, 9(6):1361-4.

18. Pombo F, DíazCandamio MJ, Rodriguez E, Pombo S. Pancreatictuberculosis: CT findings. Abdom Imaging 1998; 23:394 397.[PMID:9663275]

19. Takhtani D, Gupta S, Suman K, Kakkar N, Challa S, Wig JD, SuriS. Radiology of pancreatic tuberculosis: a report of three cases. Am JGastroenterol 1996; 91:18321834.[PMID: 8792708]

20. Fischer G, Splenger U, Neubrand M, Sauerbruch T. Isolated tuberculosis of the pancreas masquerading as a pancreatic mass. Am J Gastroenterol. 1995;90:222730.

21. Coelho JC, Weiderkehr JC, Parolin MB, Balbi E, Nassif AE. Isolated tuberculosis of the pancreas after orthotopic liver transplantation. Liver Transplantation and Surgery. 1999;5:153-5.

22. Rana SS, Bhasin DK, Srinivasan R, Sampath S, Mittal BR, SinghK. Distinctive endoscopic ultrasound features of isolated pancreatictuberculosis and requirements for biliary stenting. Clin Gastroenterol Hepatol 2012;10:323-325. [PMID: 22037426]

23. Sharma V, Rana SS, Bhasin DK. Endoscopic ultrasound guidedfi ne needle aspiration for diagnosis of pancreatic tuberculosis. JOP2013;14:521. [PMID: 24018601]

24. Rao C, Rana SS, Bhasin DK. Endoscopic ultrasound and pancreatictuberculosis. J Gastrointestin Liver Dis 2012;21:439-440. [PMID:23256131]

25. MartínezAQ, DeCruz P, Murugananthan A, Desmond P, Chen R.Endoscopic ultrasound-guided fine needle aspirate: a useful method inthe diagnosis of pancreatic tuberculosis. ANZ J Surg 2012; 82:282-283.[PMID: 22510191]

26. Chatterjee S, Schmid ML, Anderson K, Oppong KW. Tuberculosis and thepancreas: a diagnostic challenge solved by endoscopic ultrasound. A caseseries. J Gastrointestin Liver Dis 2012; 21:105-107. [PMID: 22457868] 
27. Levine R, Tenner S, Steinberg W, Ginsberg A, Borum M, HuntingtonD. Tuberculous abscess of the pancreas. Case report and review of the literature. Dig Dis Sci 1992; 37:1141-1144. [PMID: 1618064]

28. Ahlawat SK. EUS-guided FNA diagnosis of pancreatic tuberculosis. Gastrointest Endosc 2007; 65:557-558. [PMID: 17321273]

29. Coriat $R$, Latournerie $M$, Galtier JB, Michiels C, Hillon P, Manfredi S.The role of echoendoscopic biopsy in diagnosing tuberculosis of pancreas.Gastroenterol Clin Biol 2008; 32:98-101. [PMID:18341981]

30. Song TJ, Lee SS, Park do H, Lee TY, Lee SO, Seo DW, Lee SK, Kim MH.Yield of EUS-guided FNA on the diagnosis of pancreatic/peripancreatictuberculosis.

Gastrointest Endosc 2009; 69: 484491.[PMID:19231490]

31. Morris DL, Wilkinson LS, al Mokhtar N. Case report: emphysematous tuberculous pancreatitis diagnosis by ultrasound and computed tomography. Glin Radiol. 1993;48:286-7

32. Desai DC, Swaroop VS, Mohandas KM, et al. Tuberculosis of the pancreas: report of three cases. Am J Gastroenterol. 1991;86:761-3.

33. Meesiri S. Pancreatic tuberculosis with acquired immunodeficiencysyndrome: a case report and systematic review. World J Gastroenterol 2012; 18:720-726. [PMID: 22363146] 